\title{
Redesign Prototype of Fintech Application
}

\author{
A F Doni *, Y D P Negara, Eka Retno Wulandari, and Muhamad Zainul Mustofa
}

Departement of Informatic Engineering, University of Trunojoyo Madura, Indonesia

\begin{abstract}
The development of Fintech's business in Indonesia helps maximize the use of technology to change, sharpen, or improve various financial aspects ranging from payment methods, transferring funds, obtaining funds, loans to asset management can begin to be accelerated and shortened using technology. However, considering technology that is not well prepared will have an impact on a poor user experience. The DANA application still requires UI / UX difficulties on transactions so it does not meet user expectations. Assessing user-centered design can help in user-related issues. Supporting user-centered design has been supported by various techniques, methods, tools, procedures and processes that help design interactive systems that are more user-centered. Data mining methods used are interviews with end users and literature studies. New design and prototype recommendations according to usability test results. A total of seven participants tested the usability of the new transaction prototype. The expected results of this design help overcome/control the user in conducting transactions.
\end{abstract}

Keywords: Fintech application, Data mining methods, User-centered design

\section{Introduction}

At present the Startup business is growing so rapidly one of them is fintech (Financial technology) [1][2]. The emergence of fintech helps maximize the use of technology to change, sharpen, or accelerate various aspects of financial services ranging from payment methods, fund transfers, fund collection, loans to asset management can then be accelerated and shortened using technology [3][4].

In Indonesia, there are currently around 113 fintech startups registered with OJK. One of them is the DANA application [5]. DANA application (Dompet Digital Indonesia) [6] is a digital payment service on an open platform basis[7]. FUNDS are useful for storing money online or as a digital wallet[8], this application offers several services to support various electronic transactions, such as e-commerce transactions, top-up credit, electricity bill payments, and other transactions [9][10].

To win the fierce startup business competition, it is necessary to improve the quality of one of them through the user interface[11]. The purpose of the user interface is to improve usability and of course user experience. User Interface and User Experience (UI/UX) play an important role in the development of an application because the design of an application must be neat and organized [12]. Besides the User Interface and User Experience (UI/UX) must be in accordance with user requirements of the application to be built. User Interface and User Experience (UI/UX) are built by looking at the user needs

\footnotetext{
* Corresponding author : doni.fatah@trunojoyo.ac.id
}

for an application that will be built starting from the display design, features, and various other needs[12].

The DANA application still has shortcomings in UI/UX. These deficiencies regarding the features/menus available are incomplete so users have difficulty when they want to do something. For example, when a user wants to cancel a payment transaction, the user cannot cancel it and has to wait $1 \times 24$ hours for the order to be automatically canceled and also when the user wants to delete the transaction history the user cannot do so because there is no option/option to delete the transaction history. The redesign on the user interface needs to be done to facilitate the user in the transaction and increase the value of user experience[13].

The user-centered design approach can help in problems related to the user[14]. The user-centered design approach has been supported by a variety of techniques, methods, tools, procedures, and processes that help design interactive systems that are more user-centered. Data mining methods used are interviews with end-users and literature studies [15]. New design and prototype recommendations refer to the results of usability testing. The expected outcome of this design is to help overcome the difficulties/ constraints of the user in making transactions.

\section{Method}

The method used in the study in accordance with the problems to be solved in this study is an incomplete feature on the payment menu. How to find solutions to 
improve user experience by designing interactions and interfaces according to user needs [16].

The scope of the issue discussed is part of the payment transaction where there is no transaction cancellation feature and clear transaction history. To solve these problems the user-centered design method is used in the initial and final stages of analysis[17]. User-centered design (UCD) is a general term that describes the design process where users are involved in the design formation[18]. Many describe how users are involved in the UCD process, but the most important concept is that users are involved in one or more things. The stages of this research refer to the four stages used to design[19].

\subsection{Stage 1 - Reference Study}

The reference study phase is the stage the first is aimed at exploring information about fintech and the application of DANA through journals and papers both nationally and internationally.

\subsection{Stage 2 - Design of the sitemap}

Information architecture or sitemap is a description of the information displayed on the website. The purpose of information architecture is to give users an idea of what they can do on the website and make it easier for users to perform tasks or access information needed. In short, IA represents menus and submenus that are used by users to perform a task.

\subsection{Stage 3 - Existing System Analysis \& Value Proposition Canvas}

At this stage, an analysis of the existing system/application interaction design is carried out. In analyzing the interaction design things that must be known include the use of the application, the context of application use, target users, user goals, and business objectives. then it must be understood in advance how the system in the DANA application runs [20], its features, how it works, and look for problems related to a user experience that might arise. Problems with UX are not only about the design of the user interface but also includes the ease and comfort of users when using applications/systems. Then we make a recapitulation of the results of mapping or analysis using Value Proposition Canvas.

\subsection{Stage 4 - User Research and Persona \& Recap. of User Journey Mapping}

Make a simple user research plan that aims to explore feedback from end-users. The method to be used is interviews with respondents who have used the DANA application. From the results of this interview obtained information about user experience when using the DANA application, complaints/difficulties of users when using the DANA application [21]. Next, we create a persona that comes from respondents who have been interviewed. Persona functions so that we understand the user's character so that it can help us in making application designs. Finally, the recapitulation of the results of mapping the problems found, into User Journey Mapping. In the User Journey, Mapping Data obtained are then analyzed in order to obtain a picture of the problems and needs and then provide solutions to user difficulties.

\subsection{Stage 5 - Making the Wireframe Prototype}

This stage is the stage to get as many ideas as possible in designing a product with reference to the results of the previous analysis. At this stage, we can design the interaction design including making information architecture, making low-fidelity / wireframing, making prototypes then doing usability testing to check the effectiveness of designs that have been made[22].

A wireframe is a concept or blueprint design of the application design to be made. Wireframes function to describe the workflow of a task or feature and display any information that needs to be displayed on each page. Wireframes usually do not pay attention to aesthetics or beauty visually. Visual beauty will be done in the highfidelity design phase. The creation of a wireframe must refer to the sitemap or menu frame that has been created. A prototype is a stage to implement the design in the form of prototypes of the best ideas that have been selected at the decide stage. The prototype produced at this stage is in the form of a high-fidelity prototype so that it can be used in interacting with users[19].

\subsection{Stage 6 - Usability Testing}

Usability testing is one of the design processes in UCD which is carried out to find out whether a product meets the usability criteria by involving users in testing. The redesigned interface design must be able to solve the UXrelated problems that have been previously defined[15].

\section{Result and Discussion}

The discussion of this research is carried out in several stages to produce application designs according to user needs.

\subsection{Design of Information Architecture}

On the Funds menu application available are Home, History, Pay, Pocket, and Me. On the homepage menu, there are 4 sub-menus namely scan, fill balance, send, request. On the scan menu, there is a $\mathrm{QR}$ scan which is useful when making payment transactions using a $Q R$ code. In the top-up/balance menu, the balance using the code can be via debit card, bank transfer, agent, and others. On the send menu, we can send money to users of FUN through the QR code scan or using a telephone number. In the menu ask to be used when going to collect money or joint venture with us to determine the nominal amount. Friends can use the QR code or via the link sent via Whatsapp / other apps. In addition to the sub-menu on the homepage, we can also see the contents of the balance and notifications as well as various options if the user 
wants to make payments/purchases of credit, electricity, water, BPJS, and so on.

In the history menu, there are two sub-menus, namely in progress and completed. The in-progress sub-menu displays the history of transactions that are being carried out or have not been paid while completed, which contains a number of completed or failed transactions.

On the pay menu, we can make payments using a QR code scan or by using a user card given a transaction number that can be paid through a bank or credit card.

In the pocket, the menu contains various vouchers. Vouchers are obtained from FUNDS. To be able to do this game, users must have made transactions using the DANA application. In the pocket menu, there are a number of sub-menus such as vouchers, games, will expire, and others.

Finally, there is my menu. On my menu, there is user account information, user QR code, and re-verification (premium), underneath there, are also subcategories of feature categories such as balances, saved cards, and manage bills. In addition, there are subcategories of general information categories such as tutorials, help center, terms and conditions, privacy policy. And finally, the application settings category sub-menu which contains settings, app version, and exits.

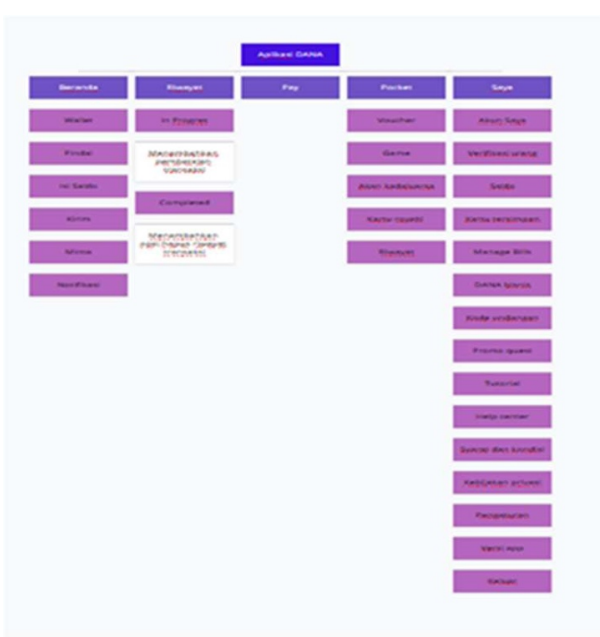

Fig.1. Information architecture can be described in a Sitemap or Menu Structure

This design was made after going through the process of identifying user needs through system analysis, task analysis, and user research of 7 users of the DANA application. After doing this process, several complaints were obtained from users of the DANA application, which made users uncomfortable using it. The following is the recapitulation of the problem mapping using user journey
Table 1. Various obstacles encountered by users in the DANA application and its solutions

\begin{tabular}{|c|c|c|c|}
\hline No & $\begin{array}{c}\text { New } \\
\text { difficulties / } \\
\text { needs }\end{array}$ & $\begin{array}{c}\text { User's } \\
\text { Thoughts / } \\
\text { Emotion }\end{array}$ & Opportunity \\
\hline 1 & $\begin{array}{l}\text { There is no } \\
\text { order } \\
\text { cancellation } \\
\text { feature }\end{array}$ & $\begin{array}{l}\text { Sad, } \\
\text { disappointe } \\
\text { d }\end{array}$ & $\begin{array}{l}\text { Add an order } \\
\text { cancellation feature } \\
\text { in the Payment } \\
\text { Options } \\
\text { section }\end{array}$ \\
\hline 2 & $\begin{array}{l}\text { Absence of } \\
\text { erasing } \\
\text { transaction } \\
\text { history } \\
\text { feature }\end{array}$ & $\begin{array}{l}\text { disappointe } \\
\text { d }\end{array}$ & $\begin{array}{l}\text { Add the delete } \\
\text { history per } \\
\text { transaction feature }\end{array}$ \\
\hline 3 & $\begin{array}{l}\text { Too many } \\
\text { advertisement } \\
\mathrm{s}\end{array}$ & angry & $\begin{array}{l}\text { Reduces } \\
\text { advertisements that } \\
\text { appear }\end{array}$ \\
\hline 4 & $\begin{array}{l}\text { Barcodes } \\
\text { cannot be } \\
\text { read when } \\
\text { transferring } \\
\text { money }\end{array}$ & $\begin{array}{l}\text { Angry, } \\
\text { annoyed, } \\
\text { disappointe } \\
\text { d }\end{array}$ & $\begin{array}{l}\text { Check the barcode } \\
\text { if there are } \\
\text { stains/dirt covering } \\
\text { the QRcode, clean } \\
\text { the user's camera, } \\
\text { check the internet } \\
\text { connection }\end{array}$ \\
\hline
\end{tabular}

According to the table 1, there are various obstacles encountered by users in the DANA application and its solutions. Constraints contained in the DANA application include: the user has difficulty when scanning for payment, the user cannot cancel the transaction and also cannot delete the transaction history.

For constraints in the field of user interface related to the absence of buttons/options for canceling and deleting transaction history, a redesign of the DANA application by adding the cancel transaction feature in the payment feature also adds a delete history feature in the transaction history display. Before redesigning the application, make a persona first. Personas made can help in making application redesign.

\subsection{Making application redesign}

In making application redesign after making analysis and persona, we make wireframes. A wireframe is a rough framework or sketch for structuring items on web pages before the actual design process begins. To design the UI Designer wireframe, you can use handprints on paper or use special wireframing design tools. Visually the wireframe is only in the form of lines and boxes that govern the layout of the elements on the website. With the wireframe, web developers are greatly helped by their work so that the development process can be structured and directed. 


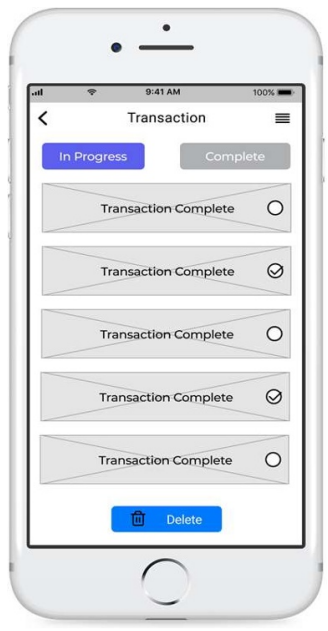

Fig.2. Wireframe image after changing is located in the complete transaction history

After redesigning, the modified wireframe is to add a button to delete part or all of the transaction history. With the addition of this button, the user can have the choice of wanting to delete part or all or not delete the transaction history at all.

What is done after designing a wireframe is usability testing to evaluate the design results. The scenario carried out in conducting usability testing asks a few questions beforehand to the user. The question begins with the introduction and purpose of this usability testing. After that continued with questions about the redesign that will be carried out on this application.

\subsection{Design Improvements}

Based on the results of usability testing, improvements made are to add the order cancellation button to the transaction history in progress and add the option / delete history button to the completed transaction.

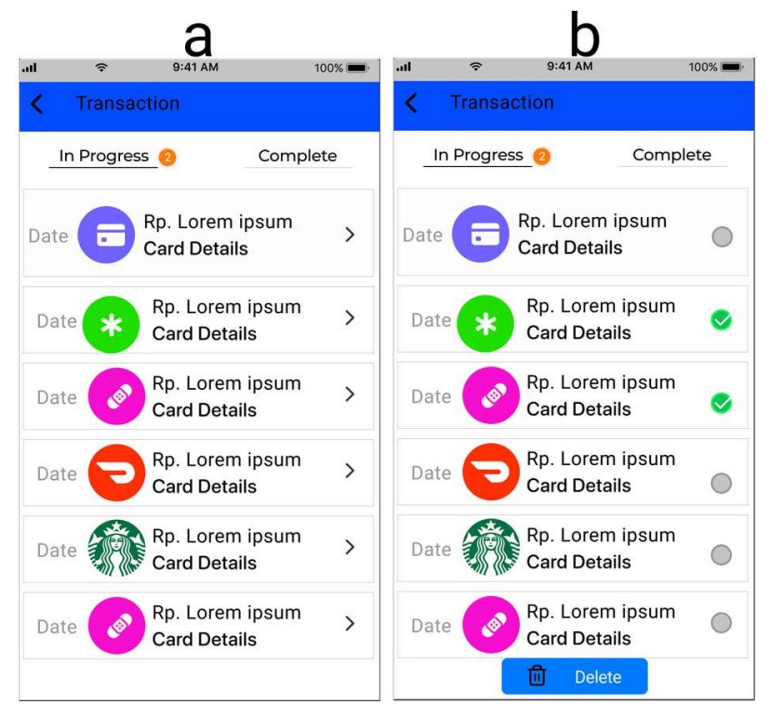

Fig.3. (a) Preliminary Transaction Design, (b) Design improvements with the addition of a menu to delete transaction history
Figure 3, repair 1 there is no option to delete transaction history, explains the difference between (a) the Initial Design of the Transaction, so it is an image before the change, then for the image (b) is the improvement of the design by adding a menu to delete transaction history in the application.

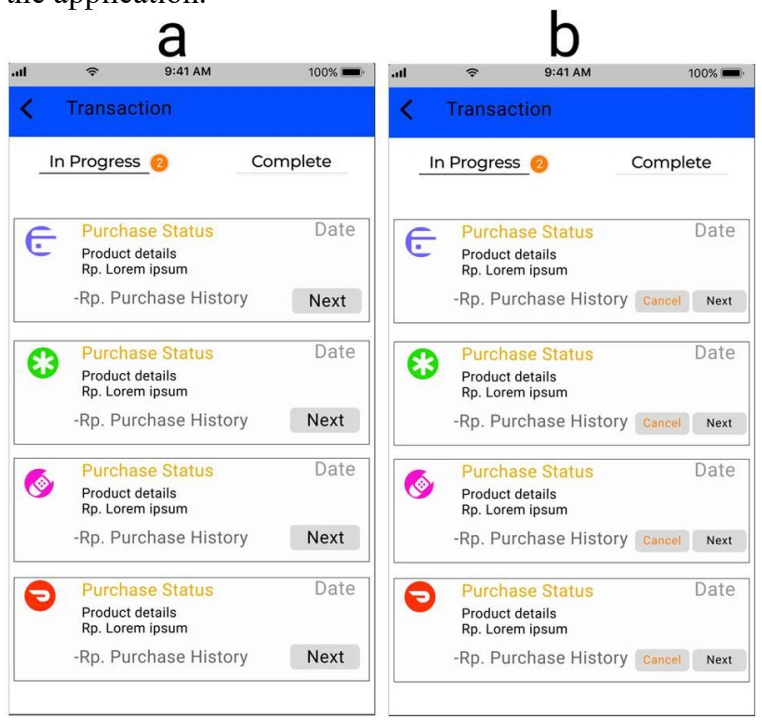

Fig.4. (a) Initial Design of Transaction Process, (b) Design Improvements with the addition of the Transaction order cancellation menu.

Figure 4 describes the 2nd Improvement on the transaction menu, where there is no order cancellation, in point (a) explains the Initial Design of the Transaction Process, in point (b) is Design Improvement by adding a cancellation menu for Transaction orders

\section{Conclusion}

From the discussion that has been done, it can be concluded that in the DANA application there are still some shortcomings in terms of UI / UX. These deficiencies regarding the features/menu of the availability of the menu Clear transaction history and order cancellation menu, so that the proposed design improvements using the User-centered design (UCD) method where the proposed improvement design results, then conducted Usability Testing by distributing questionnaires and interviews resulting in an average of resource persons feeling agree with some additional menu proposals on the transaction and provide satisfaction for users and facilitate users in making transactions.

\section{References}

[1] A. Iradianty and B. R. Aditya, "Indonesian Student Perception in Digital Payment," $J$. Manaj. Bisnis, vol. 17, no. 4, pp. 518-530, 2020, doi: 10.38043/jmb.v17i4.2713.

[2] P. Hanafizadeh and S. Marjaie, "Exploring banking business model types: A cognitive view," Digit. Bus., vol. 1, no. 2, p. 100012, 2021, doi: 10.1016/j.digbus.2021.100012. 
[3] S. Turki, "The Role of Marketing Information System on Decision Making: An Applied study on Royal Jordanian Air Lines (RJA).," Int. J. Bus. Soc. Sci., vol. 2, no. 3, pp. 175-185, 2011, [Online]. Available: www.ijbssnet.com.

[4] D. Lopes-Teixeira, F. Batista, and R. Ribeiro, "Spatio-temporal analysis of brand interest using social networks," Iber. Conf. Inf. Syst. Technol. Cist., vol. 2018-June, pp. 1-6, 2018, doi: 10.23919/CISTI.2018.8399241.

[5] W. Widiyanti, V. Islami, R. -, S. -, and R. -, "OVO E-Wallet as a Platform of Digital Payment in Indonesia: An Empirical Analysis," Monet. - J. Akunt. dan Keuang., vol. 7, no. 2, pp. 237-241, 2020, doi: 10.31294/moneter.v7i2.9542.

[6] R. M. Acelian, "Analysis of Sales Promotion, Perceived Ease of Use and Security on Consumer Decisions to Use DANA Digital Wallet," Int. J. Innov. Sci. Res. Technol., vol. 6, no. 1, pp. 14361441, 2021, [Online]. Available: https://ijisrt.com/assets/upload/files/IJISRT21JA N622.pdf.

[7] D. S. Soegoto and M. P. Tampubolon, "E-Wallet as a Payment Instrument in the Millennial Era," IOP Conf. Ser. Mater. Sci. Eng., vol. 879, no. 1, 2020, doi: 10.1088/1757-899X/879/1/012139.

[8] P. Hanafizadeh and S. Kim, "Digital Business: A new forum for discussion and debate on digital business model and digital transformation," Digit. Bus., vol. 1, no. 1, p. 100006, 2020, doi: 10.1016/j.digbus.2021.100006.

[9] S. Isrososiawan, R. Hurriyati, and P. D. Dirgantari, "User Mobile Payment Behavior Using Technology Acceptance Model (TAM): Study of 'Dana' E-Wallet Users," J. Minds Manaj. Ide dan Inspirasi, vol. 6, no. 2, p. 181, 2019, doi: 10.24252/minds.v6i2.11274.

[10] K. Subaramaniam, R. Kolandaisamy, A. Bin Jalil, and I. Kolandaisamy, "The impact of E-Wallets for current generation," J. Adv. Res. Dyn. Control Syst., vol. 12, no. 1 Special Issue, pp. 751-759, 2020, doi: 10.5373/JARDCS/V12SP1/20201126.

[11] J. Herdioko, P. B. Titalessy, and B. E. Krisanta, "Motivation of the Use of Digital Wallets in Young Generations in the Time of the Covid-19 Pandemic," Arch. Bus. Res., vol. 9, no. 1, pp. 116127, 2021, doi: 10.14738/abr.91.9595.

[12] P. Vilar, "Designing the User Interface: Strategies for Effective Human-Computer Interaction (5th edition)," JASIST, vol. 61, pp. 1073-1074, 2010, doi: 10.1002/asi.21215.

[13] T. Raihan and I. S. Indira Rachmawati, "Analyzing Factors Influencing Continuance Intention of E-Wallet Adoption Using Utaut 2 Model (a Case Study of Dana in Indonesia)," $e$ Proceeding Manag., vol. 6, no. 2, pp. 3717-3717, 2019.

[14] D. A. Fatah, "Evaluasi Usability dan Perbaikan Desain Aplikasi Mobile Menggunakan Usability
Testing dengan Pendekatan Human-Centered Design (HCD)," Rekayasa, vol. 13, no. 2, pp. 130-143, 2020, doi: 10.21107/rekayasa.v13i2.6584.

[15] H. B. Santoso, M. Schrepp, R. Yugo Kartono Isal, A. Y. Utomo, and B. Priyogi, "Measuring user experience of the student-centered E-learning environment," J. Educ. Online, vol. 13, no. 1, pp. 1-79, 2016.

[16] T. Forte, Jonas, Darin, “User Experience Evaluation for User Interface Redesign: A Case Study on a Bike Sharing Application," Lect. Notes Comput. Sci. (including Subser. Lect. Notes Artif. Intell. Lect. Notes Bioinformatics), vol. 10290 LNCS, pp. 347-356, 2017, doi: 10.1007/978-3319-58640-3_44.

[17] A. Bangor, T. Staff, P. Kortum, J. Miller, and T. Staff, "Determining what individual SUS scores mean: adding an adjective rating scale," Determ. what Individ. SUS scores mean adding an adjective Rat. scale, vol. 4, no. 3, pp. 114-123, 2009.

[18] P. C. C. M. J. S. E. N. Shneiderman B. and N. Diakopoulos, "Designing the User Interface: Strategies for Effective Human-Computer Interaction, 6th Edition," JASIST, vol. 61, pp. 1073-1074, 2016, doi: 10.1002/asi.21215.

[19] I. S. Junus, H. B. Santoso, R. Y. K. Isal, and A. Y. Utomo, "Usability evaluation of the student centered e-Learning environment," Int. Rev. Res. Open Distance Learn., vol. 16, no. 4, pp. 62-82, 2015, doi: 10.19173/irrodl.v16i4.2175.

[20] D. Pertiwi, W. Suprapto, and E. Pratama, "Perceived Usage of E-Wallet among the Y Generation in Surabaya based on Technology Acceptance Model," J. Tek. Ind., vol. 22, no. 1, pp. 17-24, 2020, doi: 10.9744/jti.22.1.17-24.

[21] A. S. Kustono, A. Y. A. Nanggala, and I. Mas'ud, "Determinants of the Use of E-Wallet for Transaction Payment among College Students," J. Econ. Business, Account. Ventur., vol. 23, no. 1, pp. 85-95, 2020, doi: 10.14414/jebav.v23i1.2245.

[22] G. S. Akbar, E. R. Kaburuan, and V. Effendy, "User interface (UI) design of scheduling activity apps for autistic children," Proc. 2017 Int. Conf. Orange Technol. ICOT 2017, vol. 2018-Janua, pp. 129-133, 2018, doi: 10.1109/ICOT.2017.8336105. 